\title{
Pseudo-occupational asthma
}

\author{
K M VENABLES, A G DAVISON, K BROWNE, A J NEWMAN TAYLOR \\ From the Department of Occupational Medicine, National Heart and Lung Institute, Brompton Hospital, \\ London
}

\begin{abstract}
A case is reported in which a pattern of work related asthma in a record of peak expiratory flow was artefactual. The patient had pronounced morning dips, which she recorded on working days, when she made the first recording at $0700 \mathrm{~h}$, but not on holiday, when she stayed in bed longer. The case emphasises the need for clear instructions to patients about peak flow records.
\end{abstract}

Patients' self recording of peak expiratory flow (PEF) gives information about changes in the severity of asthma with treatment and in relation to environmental exposure. The use of these records in the diagnosis of occupational asthma was described by Burge ${ }^{1}$ and reviewed recently. ${ }^{2}$

\section{Case report}

A woman of 46 had worked as a solderer for 14 years. She had asthma, which started two years before her exposure to solder and did not improve at weekends or during holidays. Solder fume provoked cough. She took regular inhaled bronchodilators and corticosteroids. She had smoked 10-60 cigarettes a day for 32 years. Her father also had asthma.

She was given a Wright mini meter and verbal and written instructions about making a PEF record for four weeks, which included a two week holiday. The instructions said, "Please measure your breathing every two hours of every day, starting as soon as you wake up and going through the day until you go to bed." The subsequent graph of daily mean, maximum, and minimum PEF showed diurnal variation ((maximum - minimum)/maximum) of up to $53 \%$ and, apparently, great improvement while she was on holiday and deterioration at work (fig 1), though her symptoms and treatment requirements had not changed. The deterioration at work was largely explained by a lower minimum PEF; there was little change in maximum or mean PEF.

On being questioned she said that on work days she recorded her PEF immediately on waking and rising at 0700 hours. During holidays she woke at $0700 \mathrm{~h}$ but got up at $0900 \mathrm{~h}$, when she recorded her first PEF, thus missing the morning dip. PEF was similar at work and during holidays (fig 2) except at $1100 \mathrm{am}$, when it was significantly lower at work ( $t$ test), but she took no medication from 0800 to $1230 \mathrm{~h}$ at work. Her FEV, varied from 0.6 to 1.31 , too low for safe inhalation challenge testing.

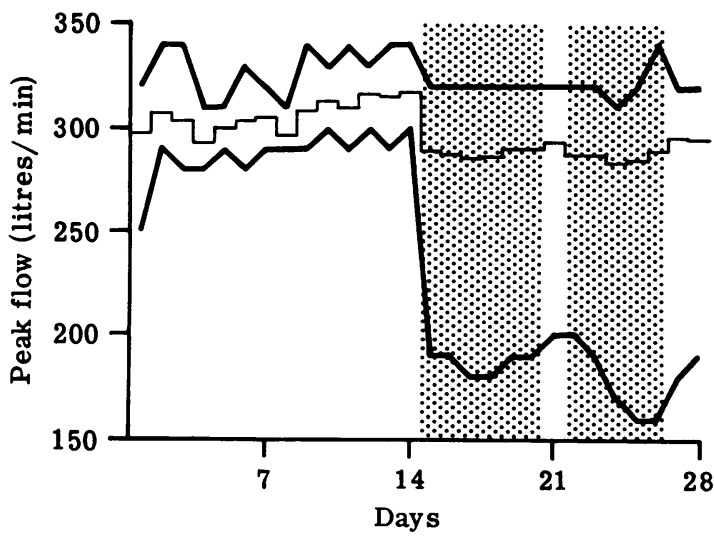

Fig 1 Daily mean, maximum, and minimum peak expiratory flow (PEF) with days at work shaded.

Address for reprint requests: Dr K M Venables, National Heart and Lung Institute, London SW3 6HP.

Accepted 13 June 1989

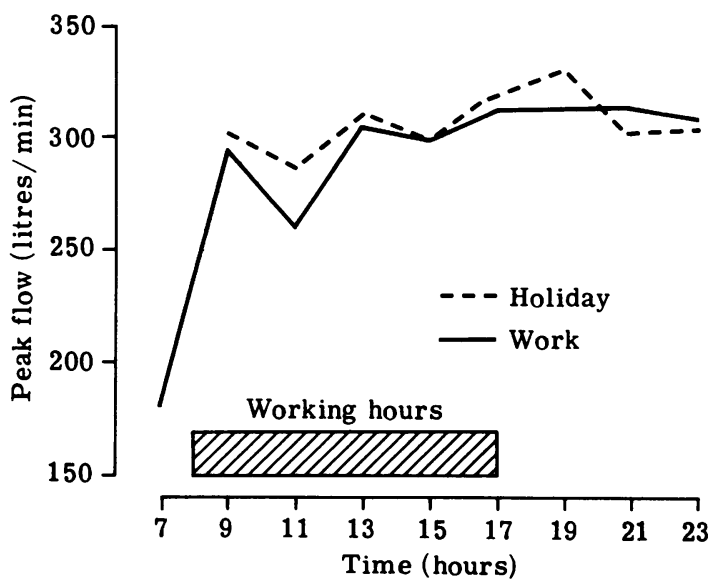

Fig 2 Mean peak expiratory flow (PEF) through the day during a holiday and in the working week (weekends omitted). Recording started at 7.00 am on work days but at 9.00 am during the holiday. 


\section{Discussion}

Solder fumes containing colophony are a well recognised cause of asthma ${ }^{3}$ but the patient's history made it unlikely that her asthma was caused by solder fumes. Her PEF graph showed artefactual work related asthma, "pseudooccupational asthma," which appears to be unusual. False negative PEF records are more common, usually because the period away from work is too short, or the patient takes more medication on work days.

This is the most striking illustration of the effects of varying the daily starting time of PEF monitoring that we have seen, and was readily detected; but more subtle effects could be misinterpreted. Patients may fail to record the morning dip during any period when they do not need to get up immediately on waking, such as weekends, holidays, or sickness absence from work, or when they are on late work shifts. The interpretation of PEF records requires that all conditions remain constant except the treatment or environmental exposure under study. It is essential that patients receive clear verbal and written instructions and that compliance is checked.

\section{References}

1 Burge PS, O'Brien IM, Harries MG. Peak flow rate records in the diagnosis of occupational asthma due to colophony. Thorax 1979;34:308-16.

2 Burge PS. Problems in the diagnosis of occupational asthma. Br J Dis Chest 1987;81:105-15.

3 Industrial Injuries Advisory Council. Occupational asthma. London: HMSO, 1980. (Cmnd 8121.) 